\title{
The Future of Japan's Health System - Sustaining Good Health with Equity at Low Cost
}

\section{Citation}

Reich, Michael R., and Kenji Shibuya. 2015. “The Future of Japan's Health System - Sustaining Good Health with Equity at Low Cost." N Engl J Med 373 (19) (November 5): 1793-1797. doi:10.1056/nejmp1410676.

\section{Published Version}

doi:10.1056/NEJMp1410676

\section{Permanent link}

http://nrs.harvard.edu/urn-3:HUL.InstRepos:32303185

\section{Terms of Use}

This article was downloaded from Harvard University's DASH repository, and is made available under the terms and conditions applicable to Other Posted Material, as set forth at http:// nrs.harvard.edu/urn-3:HUL.InstRepos:dash.current.terms-of-use\#LAA

\section{Share Your Story}

The Harvard community has made this article openly available.

Please share how this access benefits you. Submit a story.

\section{Accessibility}



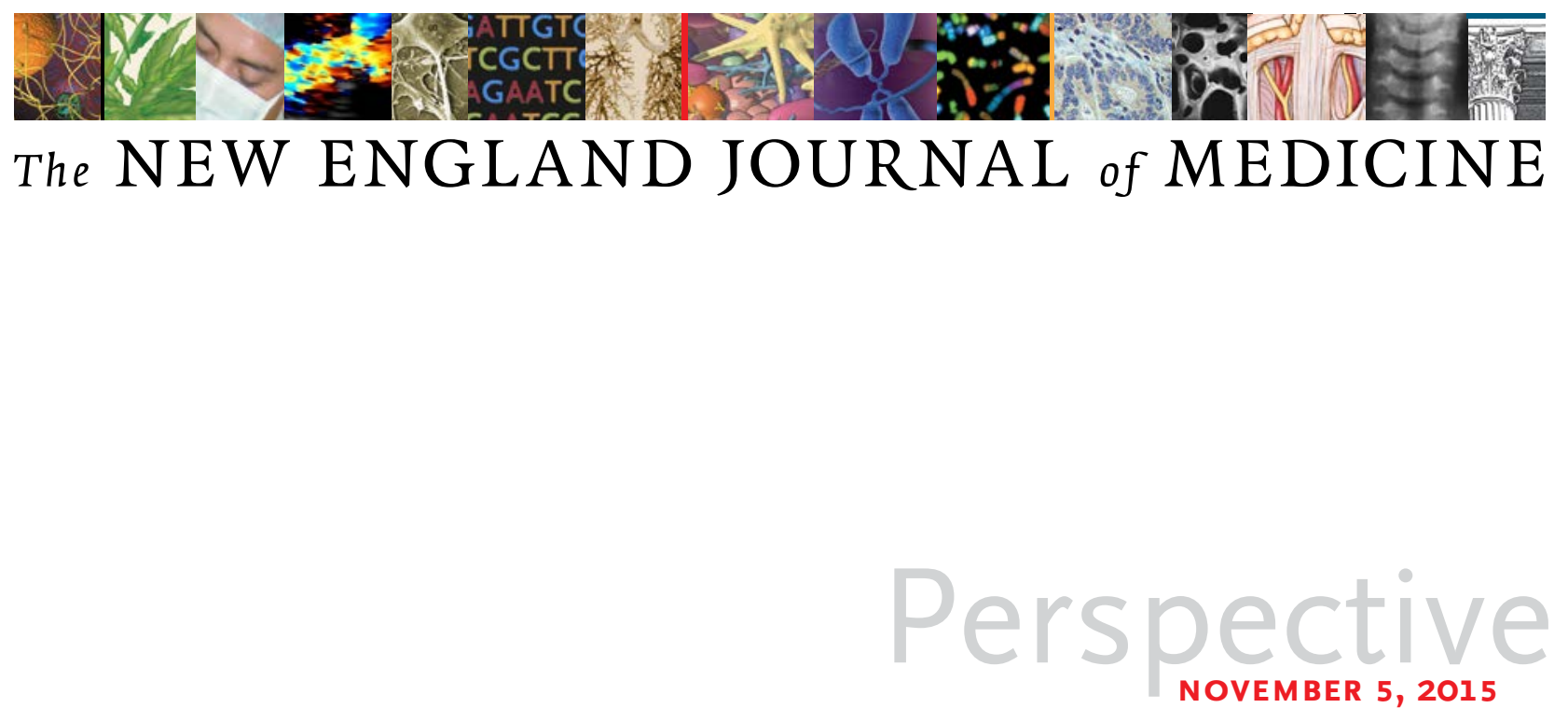

INTERNATIONAL HEALTH CARE SYSTEMS

\section{The Future of Japan's Health System - Sustaining Good Health with Equity at Low Cost}

Michael R. Reich, Ph.D., and Kenji Shibuya, M.D., Dr.P.H.

\section{Dour years ago, Japan celebrated 50 years of achieve- C ment of good health at low cost and increasing equity for its population. ${ }^{1}$ In 1961, at the beginning of a period of rapid economic development, while}

the country was still relatively poor (with a gross domestic product [GDP] half the size of Britain's), Japan reached full health insurance coverage of its population. In the next half-century, it

An interactive continued to develop graphic is its health system and available at NEJM.org improve equity, even applying this principle of universal health coverage in its global health diplomacy. ${ }^{1}$ Now, however, Japan faces serious fiscal pressure due to a sluggish economy and the rapid aging and low birth rate of its population - but it is striving to sustain its health system in the face of these challenges.
Japan followed a nonlinear path to universal coverage. Previous Japanese policymakers were sometimes motivated to develop the health system for reasons of political economy that were unrelated to health. For example, Japan's first national policy for health insurance was introduced in 1923, motivated in part by imperial visions and the desire for a strong and healthy workforce for war. During World War II, Japan achieved nearly $70 \%$ health insurance coverage. Then, in the postwar period, political competition among the major parties promoted government efforts to expand coverage, as the conservative Lib- eral Democratic Party sought to provide benefits to its rural constituents and to weaken the agendas of the Socialist and Communist parties by redistributing social resources to industrial workers. Japan was not unique in this regard: in countries such as Britain and Germany, the process of attaining universal health coverage also stretched over long periods and was advanced by various political motivations. ${ }^{2}$ Though such mixed origins don't diminish the value of Japan's health policy accomplishments, they do highlight the importance of viewing the process from historical and political perspectives.

Japan's achievements in health status are well known (see table). Since 1986, Japan has ranked first in the world in women's life expectancy at birth, which reached 87 years in 2014. Life expectancy 
Selected Characteristics of the Health Care System and Health Outcomes in Japan.:

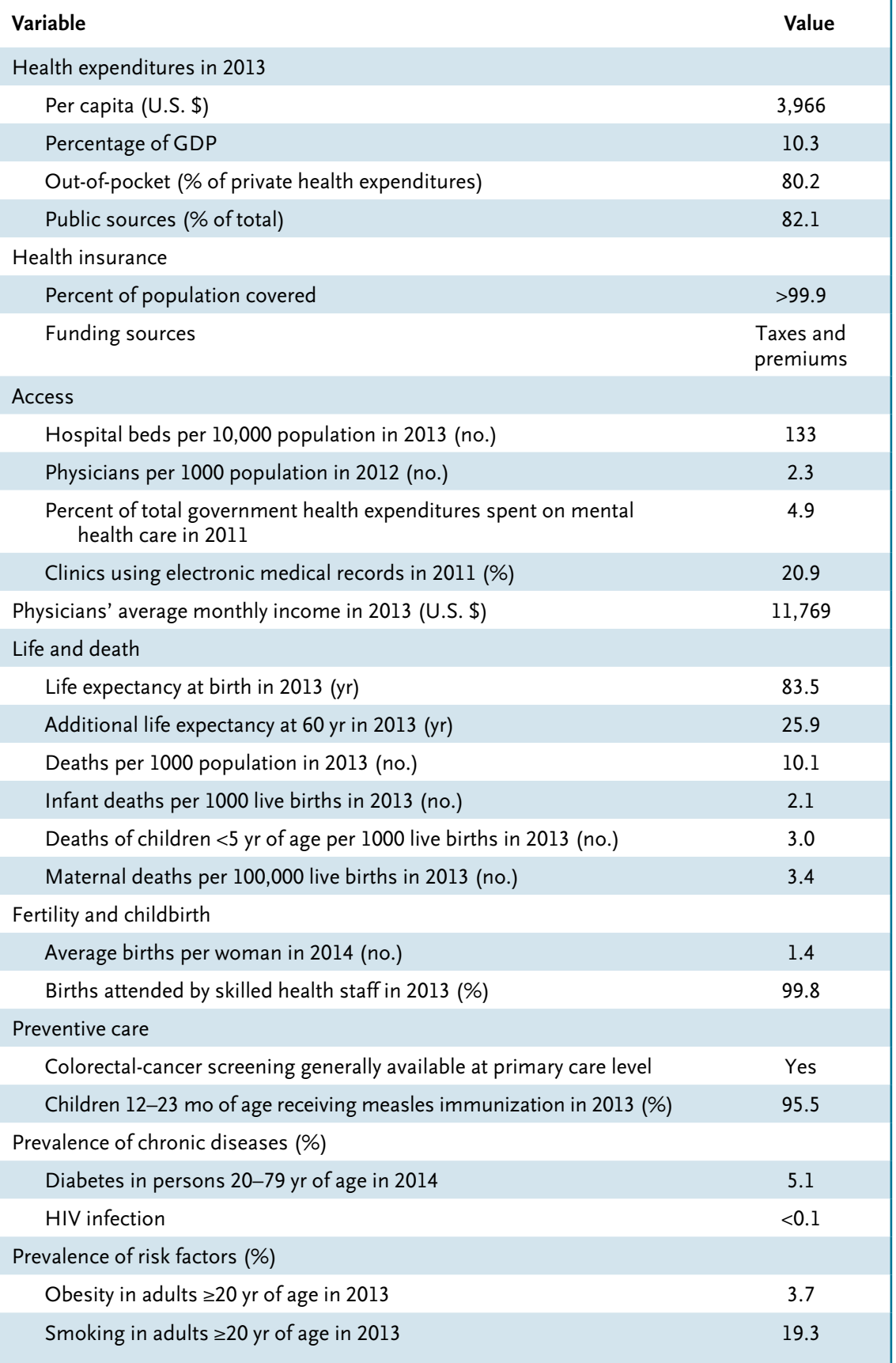

* Data are from the Organization for Economic Cooperation and Development; the World Bank, Hashimoto et al. ${ }^{3}$; the Japan Ministry of Health, Labor, and Welfare; the World Health Organization; and the National Institute of Population and Social Security Research. GDP denotes gross domestic product, and HIV human immunodeficiency virus.

for Japanese men surpassed 80 years in 2013. Japan's infant mortality rate, reported as 2.1 per 1000 live births in 2013 , is the lowest in the world. But a continuing decline in birth rate means that the country's population is shrinking, even as it ages more rapidly than in other societies. The proportion of people older than 65 years increased from around 12\% in 1990 to $25 \%$ in 2013, and the proportion of older people has exceeded the proportion of young people ( 0 to 14 years of age) since 1997. This demographic transition has created huge fiscal and health care challenges.

In addition to improving health outcomes, Japan's social insurance system has made incremental improvements in equity through cross-subsidies and tax transfers, which contributed to income redistribution in addition to risk pooling. As many countries have done, Japan expanded health coverage population group by population group, through policies designed for different groups with differing levels of coverage (both in terms of benefits and funding) - thereby creating disparities and problems of fairness. Government action and new social policy were required in order to reduce these inequities. Japan's single reimbursement fee schedule (for all physicians and patients) and single benefit package for all social insurance programs created a foundation for equity in access. The government then increased equity by changing the copayment policies for the various insurance programs, reducing benefits for employees of private companies (by increasing their copayment rates), and increasing benefits for the elderly and non-employmentbased insurance plans (by reducing their copayment rates). Policymakers thus made the overall health system more equitable over time, reflecting the value that Japanese society places on egalitarianism.

Those achievements in equity are now at risk. Japan still has about 3500 insurance plans, with 


\section{MYOCARDIAL INFARCTION}

A 55-year-old man with no serious health conditions has a moderately severe myocardial infarction.

In his suburban Tokyo home, Tanaka-san wakes up one day with chest pain. When the pain continues for 30 minutes, his family becomes worried and calls an ambulance, which arrives in 5 minutes. The emergency medicine team contacts the dispatcher, who asks a neighborhood general hospital whether there is room for an admission but is told that the coronary care unit is full. After 30 minutes of calls, the dispatcher finally finds a private hospital (with 150 beds) 20 minutes away that is willing to accept the patient.

This hospital has heart catheterization, MRI, and other equipment, and the emergency doctor in charge obtains an electrocardiogram and serum enzyme test to diagnose a myocardial infarction. A cardiologist is called to perform a cardiac catheterization, which reveals an infarction of a high lateral branch of the left anterior descending artery. A stent is immediately inserted, and reperfusion is established. The patient then stays in the hospital for 2 weeks.

The total hospitalization fee reaches $¥ 1.5$ million (U.S. $\$ 12,000$, including two heart stents for $\$ 6,700$ and facility fees of $\$ 2,500$ ). Coverage from Japan's High-Cost Medical Care Benefit System allows Tanaka-san to pay only $\$ 1,300$, to cover the fee for a singlebed room for a few nights, insurance copayments, and some extra meal fees.

The day before discharge, Tanaka-san receives instructions on medication and lifestyle counseling. He is instructed to visit the outpatient clinic 2 weeks later. Because the hospital is far from his home, the patient asks for an introduction to a nearby general practitioner. Eight months later, however, follow-up angiography to see whether any restenosis has occurred has still not been done.

Hideki Hashimoto, Masayo Matsuzaki, and Mikko Kanda contributed to this case study.

varying premium levels, so some private companies or municipalities provide better financial benefits than others. The fragmented insurance plans are differentially affected by the increasing number of elderly people in Japan. As people age and retire, they move from employment-based plans to non-employment-based plans, whose costs per person increase as older enrollees are added. As a result, non-employment-based plans increasingly have financial problems, especially as compared with Japan's employment-based plans. In an effort to reduce the financial problems for these plans and address the needs of the aging population, Japan introduced a national policy for long-term care insurance in 2000 , and in 2008 , it created a new health insurance program for people over 75 years of age.

Rising health care costs are a serious concern in Japan today: if the country takes no action, health expenditures could increase from the current $8 \%$ of GDP to around $11 \%$ by $2025 .{ }^{4}$ Rising costs are a result of structural problems in the health system, especially the rapidly aging population and the frequent use of high-cost technologies such as magnetic resonance imaging and relatively high-priced generic medicines (which cost $60 \%$ of brandname prices in Japan). Two decades of economic stagnation during the 1990s and 2000s (the "lost decades") also mean that health care costs have been taking a proportionately greater bite out of the GDP.

A final major challenge involves improving the quality of care in the Japanese system. Quality and efficiency have often been ignored by Japan's health policies. Existing government programs tend to focus on quantifying inputs and structures rather than on creating incentives to improve quality or addressing problems in outcomes. Some studies have suggested that postsurgical mortality rates in large hospitals in Japan are as low as those reported in other countries but that the quality of primary care and inpatient chronic care services may be problematic. ${ }^{3}$ Japanese hospitals and clinics are poorly differentiated by level of services, and there is no standardized benchmarking to assess hospital performance.

The Japanese government is acutely aware of these challenges and the intersecting crises of rapid aging and fiscal sustainability, which are further confounded by the health system's complex governance, including the mechanism for defining the fee schedule, as well as people's changing expectations about both medical and nonmedical aspects of health care. ${ }^{1}$ The government is trying 


\section{PREGNANCY AND CHILDBIRTH}

\section{A healthy 23-year-old woman is pregnant for the first time.}

Suzuki-san is married and lives in a Tokyo suburb. Realizing that she is pregnant, she goes to a neighborhood hospital to consult an obstetrician, who confirms the pregnancy, and she pays him $¥ 8,000$ (U.S. \$64), since pregnancy is not covered by Japan's national health insurance.

Suzuki-san next visits the nearby municipal health center. She notifies the authorities about her pregnancy and receives the Mother and Child Health Handbook, to record information from the physician's medical examination, any concerns about the pregnancy, observations about the newborn baby, and ongoing observations about the infant. She also receives a pregnancy health checkup consultation ticket and an ultrasound inspection visit ticket, which provide her with partial financial support for these antenatal services.

During her pregnancy, Suzuki-san follows the typical schedule of 14 visits for health checkups at her hospital. At each visit, she is examined by the obstetrician for risks and symptoms of pregnancy complications and meets with the midwife for nutritional and mental health care and support.

At 20 weeks, she decides on a hospital and on a vaginal delivery. After the birth, Suzuki-san stays as an inpatient for 5 days. She pays a total of $¥ 620,000$ ( $\$ 5,000$ ) for all hospital services and is reimbursed by health insurance for $¥ 420,000(\$ 3,400)$.

Two weeks after the birth, a midwife will visit Suzuki-san at home at no charge. Two weeks later, Suzuki-san will bring her infant to the hospital where she gave birth, where she will see an obstetriciangynecologist and her child will see a pediatrician.

Hideki Hashimoto, Masayo Matsuzaki, and Mikko Kanda contributed to this case study.

to find ways to ensure fiscal sustainability, in response to the commitment made by Prime Minister Shinzō Abe to eliminate deficits by 2020 . Recent laws seek to promote both the differentiation of hospitals by function and the community-level integration of medical treatment, long-term care, and preventive care by 2025. Japan is also considering a proposal to consolidate insurance plans at the prefectural level. In 2014, the Abe cabinet endorsed a government health care strategy that aims to facilitate the development of innovative technologies through a new Agency for Medical Research and Development. But these changes are not likely to be sufficient to address the profound fiscal and demographic problems facing the country. Maintaining Japan's current system by increasing premiums or taxes while cutting benefits, as was done in the past, might buy some time but it would be very costly politically and would not resolve fundamental structural problems. Incremental changes at the margins will no longer suffice.

Instead, we believe that Japan needs a new vision of health care and health systems for the future. In June 2015, an advisory panel of young experts, appointed by Health Minister Yasuhisa Shiozaki, presented its vision of health care for Japan in 2035. ${ }^{5}$ The panel's report proposes a paradigm shift for Japan's health system, to redirect its focus from inputs to outcomes, from the quantity of services provided to patients' concerns about quality, from governmental regulation to professional self-regulation, from cure to care and well-being, and from specialization of services to integrated approaches across medical and social service sectors. The new health system would continue to emphasize fairness and solidarity, while building on individual patient values and desires and emphasizing global health perspectives. ${ }^{5}$ The government, recognizing that Japan needs new solutions for its profound problems, has explicitly called on the younger generation to produce innovative ideas for improving the health system.

The hope is that Japan will be able to mobilize new ideas, systems, and technologies to assist its growing elderly population and conform to changing social values and growing structural constraints and that the Japanese government will be able to jumpstart the economy and get it growing again (using Prime Minister Shinzō Abe's strategies of government spending, monetary easing, and structural reforms, known as "Abenomics"), even as the population continues to age and shrink. More and more countries are confronting similar challenges, but Japan is first in line. Accomplishing these multiple and sometimes conflicting goals will not be easy, but that's the challenge that Japan's health system and society must tackle. 
Disclosure forms provided by the authors are available with the full text of this article at NEJM.org.

From the Department of Global Health and Population, Harvard T.H. Chan School of Public Health, Boston (M.R.R.); and the Department of Global Health Policy, University of Tokyo, Tokyo (K.S.).

1. Shibuya K, Hashimoto H, Ikegami N, et al. Future of Japan's system of good health at low cost with equity: beyond universal coverage. Lancet 2011;378:1265-73.

2. Bump JB. The long road to universal health coverage: historical analysis of early decisions in Germany, the United Kingdom, and the United States. Health Syst Reform 2015;1:28-38.

3. Hashimoto H, Ikegami N, Shibuya K, et al. Cost containment and quality of care in Japan: is there a trade-off? Lancet 2011;378:1174-82.

4. Desvaux G, Woetzel J, Kuwabara T, Chui
M, Fjeldsted A, Guzman-Herrera S. The future of Japan: reigniting productivity and growth. San Francisco: McKinsey Global Institute, March 2015

5. Japan vision: health care 2035. Tokyo: Ministry of Health, Labor and Welfare. June 2015 (http://www.mhlw.go.jp/seisakunitsuite/ bunya/hokabunya/shakaihoshou/hokeniryou 2035/future/).

DOI: 10.1056/NEJMp1410676

Copyright (c) 2015 Massachusetts Medical Society.

\section{New Math on Drug Cost-Effectiveness}

Peter B. Bach, M.D., M.A.P.P.

$\mathrm{N}$ owadays, the reality of exorbitant drug pricing overshadows even the most exceptional stories of drug efficacy. It's true that we're making huge biomedical strides, yet it's also true that prices for new drugs are rising, as are prices of existing treatments.

A case in point is nivolumab, which, as Motzer et al. report in this issue of the Journal (pages 1803-1813), appears to extend median survival in patients with metastatic renal-cell cancer by nearly half a year. But the cost to insurers and patients of using the drug for this condition - by my estimate, around $\$ 65,000$ for Medicare beneficiaries and up to twice that for commercially insured patients - can't be ignored.

The price hurts patients, limiting their access and depleting their savings. Under the current system of insurance, many patients have to pay large sums out of pocket, and research shows that when that happens, some patients will stop taking medications even if they are very effective. ${ }^{1}$ The high costs of cancer care also drive patients into bankruptcy.

The problem is particularly acute for Medicare beneficiaries, who account for the majority of patients with cancer in the United States. For nivolumab, a drug categorized as physician-administered and thus insured under Medicare's Part B benefit, Medicare assigns $20 \%$ of the cost to the patient. Although most Medicare beneficiaries have extra insurance to cover this expense - through Medicaid, an employerbased plan, or a private-market product such as Medigap - approximately $15 \%$ do not, according to the 2011 Medicare Current Beneficiary Survey. In other words, a sizable number of Medicare patients receiving this treatment could owe about $\$ 13,000$ more than half the typical annual median income among Medicare beneficiaries, which is $\$ 24,150$ (Medicare beneficiaries who lack additional coverage actually tend to have incomes below this level).

Exacerbating this problem, Medicare sets no upper limit on coinsurance under Part B (or under Part D) even though commercial plans regulated under the Affordable Care Act do have outof-pocket maximums. Federal law prevents the maker of nivolumab (Bristol-Myers Squibb) from providing assistance to patients who cannot afford the treatment. Programs such as Genentech's for
Avastin, in which beneficiaries receive the drug free once they have spent a certain amount in a calendar year, are rare. ${ }^{2}$

Policymakers, stymied by the rising cost of drugs, might think that an approach that relies on cost-effectiveness analyses would help the health care system deal with the high price of new treatments. After all, the United Kingdom sets standards for cost-effectiveness at about $\$ 40,000$ per quality-adjusted life-year for new drugs, and overall health care spending there is a fraction of what it is in the United States.

Of course, this potential solution remains theoretical today, since Medicare cannot limit drug access on the basis of cost-effectiveness; rather, laws require Medicare to cover all cancer drugs for all uses approved by the Food and Drug Administration (FDA) or listed in recognized compendia and to pay the price the manufacturer chooses to charge. But even if Medicare could set such limits, I believe that policymakers would find limited relief from the approach.

Expensive drugs can still seem deceptively cost-effective, because of the long upward spiral we have seen in the prices of cancer treat- 